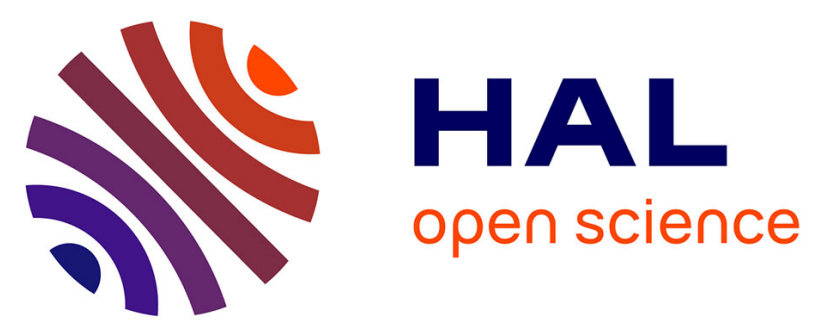

\title{
Slingram EMI Devices for Characterizing Resistive Features Using Apparent Conductivity Measurements: check of the DualEM-421S Instrument and Field Tests
}

Michel Dabas, Antoine Anest, Julien Thiesson, Alain Tabbagh

\section{- To cite this version:}

Michel Dabas, Antoine Anest, Julien Thiesson, Alain Tabbagh. Slingram EMI Devices for Characterizing Resistive Features Using Apparent Conductivity Measurements: check of the DualEM-421S Instrument and Field Tests. Archaeological Prospection, 2016, 23 (3), pp.165-180. 10.1002/arp.1535 . hal-01376280

\section{HAL Id: hal-01376280 \\ https://hal.sorbonne-universite.fr/hal-01376280}

Submitted on 4 Oct 2016

HAL is a multi-disciplinary open access archive for the deposit and dissemination of scientific research documents, whether they are published or not. The documents may come from teaching and research institutions in France or abroad, or from public or private research centers.
L'archive ouverte pluridisciplinaire HAL, est destinée au dépôt et à la diffusion de documents scientifiques de niveau recherche, publiés ou non, émanant des établissements d'enseignement et de recherche français ou étrangers, des laboratoires publics ou privés. 
4 Michel Dabas $^{1}$, Antoine Anest $^{2}$, Julien Thiesson ${ }^{2}$, Alain Tabbagh ${ }^{2}$

5 measurements: check of the DualEM-421S instrument and field tests.

${ }^{1}$ GEOCARTA, 5 rue de la banque, F-75002 ; Paris

${ }^{2}$ Sorbonne Université, UPMC-Paris 6, UMR7619-Métis, F-75252, Paris

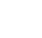

\section{Abstract} inversions were applied to the data set obtained.

Slingram EMI devices for characterizing resistive features using apparent conductivity

This paper addresses the characterization of resistive archaeological targets and near surface structures by ElectroMagnetic Induction (EMI). It presents tests achieved with the DualEM421S instrument (Dualem Inc., Canada) in order to be able to quantitatively compare these measurements to the standard technique of direct-current (DC) resistivity. The test was done over the Gallo-roman site of Vieil-Evreux in Normandy, France and 1D and 3D

We have first investigated the signal/noise ratio of each of the 6 DualEM receiver coils both in a static mode and for a quad-pulled system. The dependence on the roll angle was also measured and it is shown that rotation of DualEM must be taken into account if the roll angle is more than $\pm 10^{\circ}$. Absolute calibration and in-phase/quadrature (out of phase) component discrimination was checked by measuring the response of a small conductive and nonmagnetic sphere. Several EM soundings by measuring the instrument response at different heights were done in order to check the quadrature (out-of-phase) response of the instrument. Inversions of these EM soundings were compared to DC Vertical Electric Soundings (VESs) over 4 locations and found in accordance. Several maps using different coil configurations (HCP, VCP, PERP) and different heights were performed and inverted, both for a wide mesh 
$(5 \mathrm{~m})$ and for a finer one $(0.5 \mathrm{~m})$. The wide mesh allows a global and rapid description of the surface geology context (continuous DC measurements cannot deliver equivalent depth of investigation). The fine mesh conductivity maps clearly show the walls of a fanum (temple) as well as other structures and prove that the DualEM-421S is able to map correctly archaeological resistive targets. These maps and their interpretations were compared to previous results obtained by DC technique.

\section{Keywords}

EMI, multi-receivers, DualEM-421S, calibration, conductivity response, inversion,

\section{Introduction}

In archaeology, magnetometry is the primary technique for the detection of low resistivity earthen targets, like ditches for example, while Direct Current, DC, (earthresistance) and, more recently, Ground Penetrating Radar, GPR, predominate in the detection of resistive targets, like walls for example. Since both DC and GPR are expensive to acquire and/or process, the detection of resistive features is likely underestimated in most of the assessment of archaeological potential despite the high occurrence of resistive targets in many of the archaeological sites.

The use of earth-resistance in the field has two main drawbacks compared to magnetometry: it is more time consuming despite the development of quad-pulled systems such as ARP() (Dabas, 2009), and it might not be practical to use in areas of high contact resistance. The two main advantages of DC resistivity compared to magnetometry are the strong response of both earthen and stone built archaeological features due to a generally high electrical contrast, and also the possibility to achieve more accurate inversions using several 
depths of investigation. Globally, despite the development of electrostatic multipole arrays (Flageul et al. 2013) that fully overcame the galvanic contact limitation, the deployment of such systems remains challenging due to their weight and complexity.

EM instrumentation tends to be lighter and thus more convenient than DC instrumentation. These characteristics have made EMI a promising alternative to DC, but only recently have instruments with an accurate phase separation and with multi-receivers become readily available. These developments should open the possibility to have a conductivity inversion and also to improve the use of the in-phase response. A first study aiming at a global comparison of available instruments was done in the area of soil mapping in 2009 (Gebbers et al., 2009). In the archaeology field, only a few publications have begun to tackle the use of multi-receivers instruments (Saey et al., 2012; Bonsall et al., 2013) and none to our knowledge have studied the response of multi-receivers systems to resistive targets and compared EMI measurements with resistivity over a whole site.

Numerous archaeological sites exhibit stone built remains or compacted horizons that constitute the essence of the site and provide the key to its overall organization and evolution through time. These features, in general, correspond to a marked contrast in electrical resistivity with the surrounding soil and the DC resistivity method has been, and is, logically applied to map apparent resistivity above them. Very good results have been obtained in different climatic and chrono-cultural contexts (Papadopoulos et al. 2009, Bossuet et al. 2012) and the application of multi-depth arrays allowed exploring the depth and the thickness of the different features (Brinon et al. 2012). The sensitivity of EMI devices to resistive targets is indeed worse than that of the DC resistivity technique (Tabbagh 1986(a)) but these devices allow simultaneous measurement of the magnetic susceptibility. Susceptibility can show for example contrasts between stones and their surroundings (Gaffney et al. 2000, Saey et al. 2013), and experiments have shown the possibility of wall detection even with small coil 
separation instruments (Thiesson et al. 2009). Compared to DC deployments for a given depth of exploration, EMI instruments are more compact, which facilitates deeper investigations.

In this paper, after a field test in which noise and calibration of DualEM-421S were analyzed, we examine the results obtained with this instrument over some buried Gallo-roman walls at the site of Vieil-Evreux (Eure, France).

\section{Site presentation and reference survey}

The Gisacum religious center is located $7 \mathrm{~km}$ east of the capital city of Aulerques Eburovices (now Evreux in Normandy). There, inside a great hexagonal sacred polygon covering 230 ha, stands a series of public buildings and temples, the dwelling and craft activities being situated outside the polygon (Guyard and Lepert 1999). This site is located over a great plateau where the superficial layer corresponds to flint clay. Above this clay, of around $15 \Omega . m$ resistivity, the archaeological remains have a variable thickness and may surpass $100 \Omega . m$ in resistivity (Aubry 2003). No remains are visible at the surface, and only the thermal baths building and the main temple have been excavated.

The test took place in the area of the fanum (outlined blue rectangle in Figure 1) and to the North over a plot named 'Terre noire'. The thickness of the archaeological layer in the fanum remains around $90 \mathrm{~cm}$. The test compares the results obtained using a three-depth multipole array called ARPC (Automatic Resistivity Profiling), to those obtained with the DualEM (see description in the next paragraph).

The ARP@ is used generally for pedological and archaeological applications (Dabas, 2009); it weighs $400 \mathrm{~kg}$ and has 8 spike-wheels. The system is pulled with a quad-bike over a grass cover and the measurement location is obtained using a combination of dGPS system and a Doppler-radar system that allows checking the distance along the profile. The electrical map obtained with the ARPC system is presented in Figure 1 where all buried structures are 
clearly shown as resistive anomalies in black: walls of the Gallo-roman temple (fanum), walls around the thermal complex (peribola), dwelling houses to the West delimited by roads (via), aqueducts to the South bringing water to the thermal complex and to the temple of water (nymphea); see Dabas et al. (2005) for a complete explanation of archaeological features.

\section{Instrument and tests}

\section{Theoretical responses}

The DualEM-421S is a multi-receiver EMI instrument (DualEM sensor manual 2010) operating at $9 \mathrm{kHz}$ frequency. Its main characteristic is the provision of one horizontal transmitter loop (TX coil, Figure 2) with three pairs of receivers. In each pair, the first receiver is horizontal, allowing horizontal coplanar, $\mathrm{HCP}$, and, by rotation of all the apparatus, vertical coplanar, VCP, configuration measurements. The second receiver coil is radial to the transmitter allowing perpendicular, PERP, configuration measurements. The first pair is located at $1 \mathrm{~m}$ and $1.1 \mathrm{~m}$ from the transmitter, the second at 2 and $2.1 \mathrm{~m}$ and the third at 4 and $4.1 \mathrm{~m}$. Measurements are triggered by time (up to 10 measurements by second) and other data are available: temperature inside the tube, voltage of the battery and the two rotation angles (roll and pitch).

Considering the usual resistivity range of soils and superficial formations, the instrument belongs to the 'Low Induction Number' (LIN) EMI group (this number compares the electromagnetic diffusion range characterized by the skin depth, $\sqrt{\frac{2}{\sigma \mu \omega}}$ where $\sigma$ is the conductivity, $\omega$ the angular frequency and $\mu$ the magnetic permeability, to the geometrical dimensions of the considered problem: inter-coil spacing, depths of the targets, layer thicknesses). For this group, the conductivity response is mainly in quadrature with the primary field which facilitates the measurement of the magnetic susceptibility in phase. In Figure 3, we illustrate the theoretical variations of the coil responses (defined as the ratio of 
secondary field to primary field at the receiver coil, measured in parts per million) versus conductivity or susceptibility for a homogeneous soil. In this figure and all along the text, the responses are calculated without approximation using the complete mathematical expressions of the secondary field (Thiesson et al. 2014). The left part shows the variation of the response versus susceptibility (for a soil with a fixed $0.01 \mathrm{Sm}^{-1}$ conductivity). The right part shows the variation of the response when changing the conductivity (for a fixed susceptibility of $4010^{-5}$ SI in-phase and 0 in quadrature). The coil height is set to $0.1 \mathrm{~m}$ above ground level and the frequency to $9 \mathrm{kHz}$. It can be observed that all the dependences are quasi-linear: the sensitivity of the phase responses to the magnetic susceptibility variations are good, respectively, the sensitivity of the quadrature responses to the soil conductivity are also good. But, as frequency, soil conductivity or coil separation increases the quadrature response does not remain linear. For each transmitter-receiver separation, the conductivity limit above which the discrepancy with a linear response surpasses a $10 \%$ threshold is illustrated in Table 1 for both HCP and PERP geometries (for a $0.1 \mathrm{~m}$ height above a homogeneous ground). It must be underlined that the HCP configuration is far more affected by this limit than the PERP one. Consequently, it could be stated that, (except for 4m HCP pairs) in non-salted soils, the dependences remain linear while this relationship is altered in saline environments (Beamish 2011). It must also be noted that for greater separations $(4 \mathrm{~m})$, the amplitude of the responses generated by the soil conductivity are significantly higher than those generated by the soil susceptibility (Fig. 3): this would necessitate a very accurate phase separation of the instrument responses.

The absolute calibration was controlled by measuring the DualEM response to a small metallic conductive and non-magnetic sphere as a function to the height and distance to the transmitter coil. Comparing the theoretical response of the sphere (not detailed in this paper, see Thiesson et al. 2014) with the measured in-phase response (Figure 4a) and-b)), it appears 
that most of the points exhibits an error less than $\pm 5 \%$ except for the highest values where we can hypothesize some non-linearity in the electronics.

Using a metallic sphere, no response should be observed in the three quadrature components. Figure $4 \mathrm{c}$ and $4 \mathrm{~d}$ show that the phase separation of the devices is better than $10 \%$ (except for the points in the dashed area but which are mainly located in the area of very low amplitudes where noise is predominant). These two tests have shown that the device used is reliable and that the measurements are accurate.

The 6 receivers correspond to six different depths of investigation that permit a 6 points 'geometrical sounding' at each measurement location. Consequently, the DualEM-421 can be used in a wide variety of near surface applications: soil, environmental, engineering and archaeological studies. As with other Slingram instruments (Tabbagh 1986(c)), it also allows detecting buried metallic objects. Several studies have already been published in archaeology and soil studies (Simpson et al. 2009, Monteiro Santos et al. 2010, Saey et al. 2012, De Smedt et al. 2013) but none of them discussed in detail the ability of the instrument for $2 \mathrm{D} / 3 \mathrm{D}$ resistive features characterization.

The values displayed by the instrument are specific to the sampling volume of each transmitter-receiver configuration, but the volumes are not the same for susceptibility as for conductivity measurements. For the 6 in-phase channels, these values are directly expressed as the ratio of the secondary field to the primary field in ppt (part per thousands). For the 6 quadrature channels, they are transformed to pseudo electrical conductivity by multiplying each channel value by: $-\frac{4}{\mu_{0} \omega L^{2}}$, where $\omega$ is the angular frequency, $\mu_{0}$ the vacuum magnetic permeability and $L$ the separation between the coils corresponding to each channel. This formula is valid only for coils at $h=0$, i.e. for a center of coils at ground surface. Even if the instrument is laid on the ground, this hypothesis is not valid (the distance between the center 
of the coils and the bottom of the boom is $4,5 \mathrm{~cm})$. When the instrument is towed on a cart, the distance to the ground is $31.5 \mathrm{~cm}$.

$$
\text { Consequently: }
$$

(1) We do not use the pseudo electrical conductivities (output of DualEM), but the quadrature magnetic field ratios using Table 2 (multiplication by a series of coefficients deduced from $-\frac{4}{\mu_{0} \omega L^{2}} ;$ also quoted in DualEM-421S User's manual, 2010),

(2) One must keep in mind that the difference between the output of DualEM and the apparent conductivity is more important in HCP than in PERP and that this importance increases with the average conductivity of the soil (clayey and even more salted soils). This is a consequence of: i) greater non-linearity of the responses when the ground conductivity increases, ii) the elevation of the instrument above ground level. For example, when considering a $20 \mathrm{mS} / \mathrm{m}$ ground, the instrument at $\mathrm{h}=0.045 \mathrm{~m}$ height will measure in the HCP 4 $\mathrm{m}$ channel $-5.340 \mathrm{ppt}$ in quadrature and thus display $18.79 \mathrm{mS} / \mathrm{m}$ while at $\mathrm{h}=1 \mathrm{~m}$ (carried by the operator) it will display $15.70 \mathrm{mS} / \mathrm{m}(-4.464 \mathrm{ppt})$. Under the same conditions, the PERP $4.1 \mathrm{~m}$ channel would deliver a $-5.814 \mathrm{ppt}$ at $\mathrm{h}=0.045 \mathrm{~m}$ and display $19.5 \mathrm{mS} / \mathrm{m}$ while at $\mathrm{h}=1 \mathrm{~m}$ it would measure $-3.328 \mathrm{ppt}$ and display $11.15 \mathrm{mS} / \mathrm{m}$.

Therefore, it will be necessary to retranslate the displayed pseudo conductivity values into field ratios when attempting to retrieve quantitative results (following Thiesson et al. 2014).

\section{Field stability tests}

A cart was designed, Figure 5, to pull the DualEM-421S with a quad bike on the field at two possible clearances, 0.10 and $0.27 \mathrm{~m}$ from the bottom of the tube to the ground surface. The distance between the quad-bike and the cart was tested so that no disturbance was measured due to the presence of the quad-bike with engine switched off. 
In order to measure the potential noise due to the engine of the quad-bike, DualEM measurements were recorded continuously $(10 \mathrm{~Hz})$ during a few minutes with and without engine working (Table 3). It can be observed that the engine has no effect and that the standard deviation remains limited. PERP $1.1 \mathrm{~m}$ configuration shows a much higher deviation for an unknown reason. This experiment shows also that no "short time" drift (defined as a variation within a 5 minutes time lapse, the time that would be needed to acquire for example a $300 \mathrm{~m}$ profile at $1 \mathrm{~m} / \mathrm{s}$ ) was noticed. "Long term" drift (defined as the variations within the the entire time scale of a survey, typically several hours) was not studied here and is the subject of numerous papers ((Delefortrie et al. 2014, Dos Santos and Porsani 2011, Beamish, 2011). In archeology, we found that only "short time" drifts are really a problem because they create artefacts in the maps that superpose to the short wavelength of archaeological anomalies (typically several meters, that would correspond to a few seconds in the time domain when using a speed of acquisition of the order of $1 \mathrm{~m} / \mathrm{s}$ ). Long time drift, if ever noticed, is easily corrected by standard image filtering procedures.

The roll is another important aspect when the instrument is pulled on uneven terrain (the pitch angle also acquired with DualEM was not considered in this study). Figure 6 shows the theoretical relative quadrature out of phase signal change versus roll (grey lines). The maximum roll acceptable is 10 degrees (if we consider a maximum $2 \%$ deviation in the quadrature out of phase signal) which defines the limit that must be respected in the field, but PERP is more sensitive to the roll effect than HCP and there is a negative shift of the coil orientation by reference to the vertical. This test also allows verifying the exact coil position inside the housing tube. From the theoretical and practical point of view, the HCP configuration is less sensitive to roll because, for an $\alpha$ roll angle, the HCP emission is reduced by $\cos \alpha$ and the received field is also reduced by $\cos \alpha$ thus the HCP response is reduced by $\cos ^{2} \alpha$, but the rotation generated also a VCP response which, following the same reasoning, is 
multiplied by $\sin ^{2} \alpha$. As for small values of $h$, HCP and VCP quadrature responses are very close (the lower the instrument, the closer their values), the roll effect is very limited. On the contrary, in PERP configuration only the transmitter coil is tilted and the response is reduced in $\cos \alpha$ (Figure 6). At least, as the spacing increases, it appears that the theoretical HCP sensitivity to roll decreases, but practically appears another effect (probably due to some lack in the stiffness between the boom and the sensor itself). Fortunately, the roll variation of the signal with the PERP appears to be very repeatable and therefore could be corrected from the value of roll measured.

\section{Comparison with vertical electrical soundings}

Six DC resistivity Vertical Electrical Soundings (VES) have been achieved to recognize the vertical layering of the site (Figure 7). All exhibit the same distribution: a three layer model, where, beneath a topsoil and an 'archaeological' layer of around $1 \mathrm{~m}$ thickness and [35-40 $\Omega \mathrm{m}]$ resistivity, exists a conductive flint clay layer of thickness varying between 2 and $3 \mathrm{~m}$ and of resistivity between 10 and $20 \Omega$.m above a saturated chalk third layer of [30$40 \Omega . \mathrm{m}]$. At the same locations, the conductivity responses of DualEM-421S were recorded versus the height above ground surface. This test between $0.045 \mathrm{~m}$ and $2.25 \mathrm{~m}$ allowed, for each geometrical configuration, both to assess the noise level (by the interquartile distance) and to compare the displayed pseudo-conductivity values (transformed in ppt using the Table 1 coefficients) with the theoretical responses calculated from the VES interpreted parameters. In Table 4 the comparison for the VES number 3 is detailed where $\rho_{1}=41.3 \Omega \mathrm{m}, e_{l}=0.6 \mathrm{~m}$, $\rho_{2}=16.5 \Omega . \mathrm{m}, e_{2}=2.06 \mathrm{~m}$ and $\rho_{3}=26.9 \Omega . \mathrm{m}$.

It can be observed in Table 4 that firstly the dispersion of the measurement is limited to $1 \%$ of the response and independent of both the height above the ground surface and of the receiver orientation. Secondly, the correlation with the theoretical data is very good for the 
relative variations but exhibits different offsets for the different channels (if one hypothesizes that the gain is the same for the different channels and is accurate). Thirdly, the comparison with the approximate cumulative responses (McNeill 1980) confirms that this approximate model is not relevant for quantitative interpretation.

\section{Reminder about the investigation depths}

We do not consider here the magnetic susceptibility (in-phase responses) changes which are known to correspond to clearly lower depths of investigation than conductivity changes (Scollar et al. 1990).

The quadrature measurement sensitivity of the HCP configuration to deep horizontal layering is usually recognized as higher than that of the PERP configuration. However, the comparison of their respective abilities is more complex for a $2 \mathrm{D} / 3 \mathrm{D}$ structure: for example the ability of the PERP configuration is generally higher than that of the HCP in the 3D case (Tabbagh 1986(b)). Consequently we have decided not to use a definition which is linked to a 1D case and to approximate sensitivity functions using arbitrary levels (70\% of the total sensitivity for DOE, 'depth of exploration', and 50\% for the DOI50, DualEM manual) even if these latter permits very simple calculations. We think that the notion of investigation depth we have chosen is of better use for surveyors as it is linked to the $3 \mathrm{D}$ case, to the full calculation of the sensitivity functions, and to a standard level of 'noise' of $10 \%$. Depth of investigation is defined as to the depth where a change of more than $10 \%$ in apparent conductivity can be measured when changing the target is true electrical conductivity.

DualEM results over Terre noire (wide mesh): spatial variations observed in the superficial geologic context (1D inversion) 
In the DualEM-421S, the largest inter-coil separations allow a better characterization of the superficial geological context (the first $5 \mathrm{~m}$ approximately) than presently available mobile multi-pole resistivity systems (limited to approximately the first $2 \mathrm{~m}$ ). The $1 \mathrm{D}$ inversion process has been applied with good results in a wide variety of near-surface studies (Bendjoudi et al. 1998, Bobée et al. 2010). Even if it blurs the exact location of lateral limits of the features (Guérin et al. 1996), it is very relevant for determining the thicknesses of the different layers and their low frequency spatial variations, and in archaeological sites to evaluate the bulk thickness of the remains.

The 1D inversion (program QwInv1D, UMR METIS, using an iterative least square inversion (Guérin et al. 1996)) is here applied to the wide mesh (5m) EM data acquired in the 'Terre noire' plot (Fig. 1) with nine different data series corresponding to HCP 1m, VCP 1m, PERP 1.1m, HCP 2m, VCP 2m, PERP 2.1m, HCP 4m, VCP 4m and PERP 4.1m (all recorded at $0.27 \mathrm{~m}$ elevation and acquired continuously in two successive surveys). The original pseudo-conductivity data were pre-processed to transform them into magnetic field ratio at a height of $0.27 \mathrm{~m}$. Then, at each point of the surveyed area, the 9 experimental ratio values were inverted to obtain the 5 following parameters: resistivity and thickness of the first layer, resistivity and thickness of the second layer and resistivity of the third layer. This process was done for the whole plot (3906 points for the $5 \times 5 \mathrm{~m}^{2}$ mesh). With a modal value of $6 \%$ for the relative RMS error, the modal values of the first layer parameters are $41 \Omega \mathrm{m}$ and $1.0 \mathrm{~m}$, those of the second layer are $13 \Omega \mathrm{m}$ and $2.3 \mathrm{~m}$ and the resistivity of the third layer $39 \Omega \mathrm{m}$. The spatial variations of these parameters are presented in Figure 8. The first layer has a limited resistivity which can be interpreted by an absence of stone remains except in the northern part where such remains can be expected. A marked deep resistivity variation is present in the second and third layer; it probably corresponds to a huge change in the chalk hardness that outcrops with a reduction of the second layer thickness. 
To take into account the fact that, with the DualEM 421S, VCP configuration would necessitate a second survey, we repeat the inversion with 6 data only corresponding to HCP and PERP configurations. The results obtained are quasi -identical to those of the previous 9 data inversion with a modal value of $5.5 \%$ for the relative RMS error, $41 \Omega \mathrm{m}$ and $1.02 \mathrm{~m}$ for the first layer $12.3 \Omega \mathrm{m}$ and $2.3 \mathrm{~m}$ for the second layer and $40 \Omega \mathrm{m}$ for the third.

DualEM results over the Fanum (fine mesh): detection of 3D resistive targets (3D inversion and comparison with DC maps)

An extensive survey was done by pulling the DualEM on its cart with a $0,1 \mathrm{~m}$ clearance (only in HCP configuration for the TX coils) over the fanum. Acquisition is in a continuous mode $(10 \mathrm{~Hz})$ following parallel lines separated by $0.5 \mathrm{~m}$ and in zig-zag mode $(10 \mathrm{~m}$ between the blocks of lines). Average velocity being $6.7 \mathrm{~km} \cdot \mathrm{h}^{-1}$, the distance between acquisition points is $0.19 \mathrm{~m}$. Positioning of data is done by a GNSS system using broadcasted differential corrections from a base station situated less than $200 \mathrm{~m}$ from the fanum area. The horizontal relative accuracy is estimated around $1 \mathrm{~cm}$. The survey was done in 2 hours and 1 minute (distance covered: $12780 \mathrm{~m}$; area $0,52 \mathrm{ha}$ ). The statistics for the roll angle are such that no correction was applied (mean $=-3.8^{\circ}$, interquartile distance $=7.7^{\circ}$ ). The change of temperature was less than $2{ }^{\circ} \mathrm{C}$ during the two hours survey (median value $=24 \cdot 1^{\circ} \mathrm{C}$ ). Positioning of the data was done knowing the distance between the GPS and the different coils (Figure 2) and also the time lag between DualEM and GPS. Data, converted to apparent electrical resistivity for comparison with DC maps, were re-interpolated over a square mesh of $0.2 \times 0.2 \mathrm{~m}$ using a bi-cubic spline function. We have decided not to use any 1D or 2D filters for these data in order to show the raw data.

\section{Qualitative comparison of EM and DC maps}


In Figure 9 are presented the 6 apparent resistivity maps obtained with the DualEM, together with the two apparent resistivity maps obtained with ARPC. A stated before, no filtering was undertaken to generate these maps. No outlier points exist for the $4 \mathrm{~m}$ coils. The first outliers appear for the HCP2m coil and for both 1m coils. HCP configuration seems to be more sensitive to these shallow outliers. We think that most of these outliers come from small metallic objects spread all over the surface (the in-phase maps, not shown in this article, show high amplitude anomalies at the same position; this area is very close to an air-force base that was bombed during last world war). These outliers can be easily filtered by a 2D median filtering. Some "long term" drift does appear (see the 'bands' in PRP 4.1m for example) in these maps but does not affect the visibility of archaeological features in this case.

It can be observed that:

(1) Except for the larger coil separation in EMI, all the main resistive features are clearly delineated even if the apparent resistivity anomaly magnitudes are more limited in EMI than in DC.

(2) The apparent resistivity values are in good coherence with the depth of investigation expected from sensor geometries. The 1D point by point inversion applied in that area with a three layer model delivers the following mode values: $70 \Omega \mathrm{m}$ and $0.2 \mathrm{~m}$ for the first topsoil layer, $26 \Omega \mathrm{m}$ and $1.3 \mathrm{~m}$ for the 'archaeological' layer and $20 \Omega \mathrm{m}$ for the flint clay.

(3) As expected from both theoretical (Tabbagh 1986(b)) and physical (Frischknecht et al. 1991) models, the HCP responses are oscillating and exhibit two parallel resistivity maxima beside each wall and a stronger minimum just above it. This 'triple arch' response would be confusing when direct reading of the map in absence of $2 \mathrm{D} / 3 \mathrm{D}$ modelling reference, but it does not impede the interpretation (see below). 
(4) In agreement with the expected depths of the walls (tops at around $0.3 \mathrm{~m}$ ), the 'best' results are given by PERP $1 \mathrm{~m}$ configuration.

$3 D$ interpretation of the wall of the Cella: quantitative comparison of inverted $3 D D C$ data and DualEM data

To go further in the comparison, one can apply over a limited area, the two-step 1D/3D rapid inversion described in (Brinon et al. 2012). This process is based for 1D on an analytical forward modelling and for 3D on the moment method. The latter is relevant to quantify the responses of simple-shape features in both EM modelling, for resistivity and magnetic susceptibility contrasts (Tabbagh 1985) and in DC resistivity modelling (Dabas et al. 1991). This approach allows a direct comparison of the resistivity contrasts of the detected features.

We consider, for example, a small area limited by $X=519018.56$ and 519023.36 in easting and $\mathrm{Y}=145232.66$ and 145236.26 in northing, delineated in Figure 9, where can be observed the external cella wall. Using the data of the three channels of the ARP® one obtains for the surrounding terrain 1D model $\rho_{1}=70 \Omega \mathrm{m}, e_{1}=0.2 \mathrm{~m}, \rho_{2}=32 \Omega \mathrm{m}, e_{2}=1.3 \mathrm{~m}$ and $\rho_{3}=19 \Omega \mathrm{m}$. For the wall, the inversion gives an orientation at $100^{\circ}$ from $\mathrm{X}$ axis, a section of $1.0 \times .88 \mathrm{~m}^{2}$ for a center at $\mathrm{X}=519020.96, \mathrm{Y}=145234.46$ and $\mathrm{Z}=0.7 \mathrm{~m}$ and a resistivity of 70.5 $\Omega \mathrm{m}$. The contrast ratio between the wall and the surrounding is thus 2.2 .

Adopting these values, it is possible to calculate using the moment method the responses that would be obtained for the different DualEM coil configurations. Due to the depth of the wall, the calculations are limited to HCP 1m, HCP 2m, PERP $1.1 \mathrm{~m}$ and PERP 2.1m. The results of the comparison with the DualEM measured profile are presented in Figure 10 (Hs/Hp values in ppt) for the four coil configurations. The agreement is good both 
372 for magnitude and width. It also confirms the anomaly shapes with a single maximum in

373 PERP configuration and the three arch responses for HCP configuration.

In this example, it is clear that the walls are detected by the four coil configurations as resistive features, and would be correctly interpreted using only one of each. This result confirms what has been already established (Thiesson et al. 2009) for a smaller instrument in VCP configuration. In fact, the relative variation of amplitude of the responses above the wall is rather limited, $10 \%$ for the PERP and about $7 \%$ for HCP compared to $25 \%$ observed in the ARP@ channels. However, here again, the relevant criterion is the signal to noise ratio, i.e. the relative sensitivity of instruments to the searched-for features as opposed to the unwanted features ('geophysical noise'). In the Vieil-Evreux site where the global resistivity is of the order of $100 \Omega \mathrm{m}$ and lower, the signal to noise ratio can be comparable to that of the DC resistivity method.

\section{Conclusions}

We presented here a test of a single frequency domain EMI instrument over an archaeological site in order to better grasp the capabilities of this exploration technique. Even though this technique has been used for fifty years in archaeological survey and is sensitive to both magnetic susceptibility and electrical conductivity, it has been, and still is, less applied than magnetic and earth-resistance prospection.

The Vieil-Evreux roman site remains (mainly walls) are situated in a sedimentary (clay) geological context where the conductivity response is significantly high; consequently the two major limitations of EMI cannot be considered in the present study but they merit to be recalled in this conclusion because they, at least for a part, explain the restricted use of the technique. They are: (1) metallic objects and features disturb measurements and practically disqualify its application specially in urban contexts and (2) in highly resistive soil contexts 
the conductivity response is too small and difficult to separate from the quadrature magnetic susceptibility in the quadrature response (Tabbagh 1986(c)) in spite of recent research works aiming to overcome this problem (Simon et al. 2015).

The series of tests conducted with the DualEM in Vieil-Evreux have allowed verifying that the electronic and external electromagnetic noises are fairly rejected, the phase of the received signals are well defined, the absolute calibration is fine, the drifts limited and the roll effect characterized. Measured quadrature data are in full accordance with the theoretical complete calculations taking the true resistivities and layer thicknesses as input data (from separate VES). Using this instrument, it is thus possible to assess the advantage and drawbacks of the method itself within the particular objective of the detection of stone built resistive features.

The first point to be emphasized is that frequency domain multi-receiver EMI instruments, lighter and easier to move than multi-pole DC, can be used to characterize the superficial geological context with a sufficient depth of investigation. This aspect is important for extended archaeological sites as it allows a first rough estimation of the volume of the archaeological remains. The second point is the ability to detect and characterize walls. They are detected with $1 \mathrm{~m}$ and $2 \mathrm{~m}$ coil separations and the corresponding apparent resistivity maps clearly show the plan of the fanum at Vieil-Evreux. The corresponding signal variations are lower than with DC resistivity but as the geophysical noise is also lower, the observed signal to noise ratios are roughly equivalent. Nevertheless, referring to $3 \mathrm{D}$ theoretical modelling is required to correctly interpret the HCP raw data.

Finally the Vieil-Evreux test verifies that with sufficient fine meshing and a close referencing to modelling, stone built resistive features can be surveyed with frequency domain multireceiver EMI. 


\section{Acknowledgements}

424 We wish first to thank MADE (Mission Archéologique du Département de l'Eure) for 425 accessing this test site, GEOCARTA for giving free access to the instrument; to Rick Taylor 426 and Scott Holladay for their corrections of this manuscript and to the reviewers for their 427 helpful contributions. 


\section{References}

430 Aubry L., 2003. Acquisition, traitement et restitution des données d'une reconnaissance archéologique : la ville gallo-romaine de Vieil-Evreux. Thèse Université Pierre et Marie

432

433

Curie.

Beamish D., 2011. Low induction number, ground conductivity meters: a correction procedure in absence of magnetic effects. Journal of applied Geophysics, 75, 244-253.

Bendjoudi H., Weng P., Guérin R., Pastre J.-F., 2002, Riparian wetland of middle reach of the Seine river (France): historical development, investigation and present hydrologic functioning. A case study. Journal of Hydrology, 263, 131-155.

Bobée C., Schmutz M., Camerlynck C., Robain H., 2010. An integrated geophysical study of the western part of the Rochechouart-Chassenon impact structure, Charente, France. Near Surface Geophysics. 8-4, 259-270.

Bonsall J., Fry R., Gaffney C., Armit I., Beck A., Gaffney V., 2013. Assessment of the CMD Mini-Explorer, a new low-frequency Multi-coil Electromagnetic device, for Archaeological Investigations, Archaeological Prospection, 20, 3, 219-231.

Bossuet G., Thivet M., Trillaud S., Marmet E., Laplaige C., Dabas M.; Hulin G., Favard A., Combe L., Barres E., Lacaze S., Aubry L; Chassang M., Mourot A., Camerlynck C., 2012. City map of ancient Epomanduodurum (Mandeure-Mathay, Franche-Comté, Eastern France): contribution of geophysical prospecting techniques. Archaeological Prospection, 19, 261-280. Brinon C., F.-X. Simon, A. Tabbagh, 2012, Rapid 1D/3D inversion of shallow resistivity multipole data: examples in archaeological prospection. Geophysics, 77-3, E193-E201.

Dabas M., 2009. Theory and practice of the new fast electrical imaging system ARP®, in: Seeing the Unseen, Geophysics and Landscape Archaeology, Campana and Piro eds., CRC Press, Taylor and Francis Group, 2009, 105-126. 
Dabas M., Guyard L. and Lepert T. 2005. Gisacum revisité : croisement géophysique et archéologie. In «Géophysique et archéologie », Dossiers de l'Archéologie 308, 52-61.

Dabas M., Tabbagh A., 2003. A comparison of EMI and DC methods used in soil mappingtheoretical considerations for precision agriculture, p. 121-129, in: Precision Agriculture, ed. J. Stafford and A. Werner, Wageningen Academic Publishers, Muencheberg, 783p.

Dabas, M., Tabbagh A., Tabbagh J. 1994. 3D inversion in subsurface electrical surveying, I: Theory. Geophysical Journal International, 119, 975-990.

Delefortrie, S., De Smedt, P., Saey, T., van De Vijver, E., van Meirvenne, M., 2014. An efficient calibration procedure for correction of drift in EMI survey data. Journal of Applied Geophysics, 110, 115-125.

Dos Santos, V.R.N., Porsani, J.L., 2011. Comparing performance of instrumental drift correction by linear and quadratic adjusting in inductive electromagnetic data. Journal of Applied Geophysics, 73, 1-7.

Elwaseif, M., and L. Slater, 2010, Quantifying tomb geometries in resistivity images using watershed algorithms. Journal of Archaeological Science,37, 1424-1436.

De Smedt P., Saey T., Lehouck A., Stichelbaut B., Meerschman E., Islam M. M., van De Vijver E, van Meirvenne M. 2013. Exploring the potential of multi-receiver EMI survey for geoarchaeological prospection: a 90 ha dataset. Geoderma, 199, 30-36.

DualEM-421S User's manual, 2010, Milton, Ontario, Canada, 32p.

Flageul S, Dabas M, Thiesson J, Réjiba F, Tabbagh A. 2013. First in situ tests of a new electrostatic resistivity meter. Near Surface Geophysics, 11-3: 265-273.

Frischknecht F. C., Labson V. F., Spies B. R., Anderson W. L. 1991. Chapter 3 Profiling methods using small sources. Electromagnetic methods in applied geophysics, vol. 2, Application, part A 105-252. Edited by M. N. Nabighian, SEG, Tulsa. 
Gaffney C.F., Gater J.A., Linford P., Gaffney V.L., White R. 2000. Large-scale systematic fluxgate gradiometry at the roman city of Wroxeter. Archaeological Prospection, 7: 81-99.

Gebbers R., Lück E., Dabas M., Domsch H., 2009.Comparison of instruments for geoelectrical soil mapping at the field scale, Near Surface Geophysics, 7, 179-190.

Guérin R., Méhéni Y., Rakontodrasoa G., Tabbagh A., 1996. Interpretation of Slingram conductivity mapping in near surface geophysics: using a single parameter fitting with 1D model. Geophysical Prospecting, 44-2, 233-249.

Guyard, L, Lepert T., 1999. Le Vieil- Evreux, ville sanctuaire gallo-romaine, Archeologia $359,20-29$.

McNeill J. D. 1980. Electromagnetic terrain conductivity measurement at low induction numbers. Geonics ldt technical note TN-6, 15p.

Monteiro-Santos F. A., Triantafilis J. Bruzgulis K., 2011. A spatially constrained 1D inversion algorithm for quasi-3D conductivity imaging: Application to DUALEM-421 data collected in a riverine plain. Geophysics, 76-2, B43-B53.

Novo A., Dabas M., Morelli G., 2012: Fast High-Resolution Archaeological Mapping: STREAM X tested at Vieil-Evreux (France), Archaeological prospection, 19, 3, 179-189.

Papadopoulos N. G., Tsokas G. N., Dabas M., Yi M-J., Kim J-H., Tsourlos P., 2009. Threedimensional inversion of automatic resistivity profiling data. Archaeological Prospection, 16, 267-278.

Saey T., van Meirvenne M., De Smedt P., Neubauer W., Trinks I., Verhoeven G., Seren S., 2013. Integrating multi-receiver electromagnetic induction measurements into the interpretation of the soil landscape around the school of gladiators at Carnuntum. European Journal of Soil Science, 64, 716-727. 
Saey T., De Smedt P., Meerschman E., Islam M.-M., Meeuws F., van De Vijver E., Lehouck A., van Meirvenne M., 2012. Electrical conductivity depth modelling with a multi-receiver EMI sensor for prospecting archaeological features. Archaeological Prospection, 19, 21-30.

Scollar I, Tabbagh A., Hesse A. Herzog I., 1990, Archaeological prospection and remote sensing. Cambridge University Press, 674p.

Simon F.-X., Sarris A., Thiesson J., Tabbagh A., 2015. Mapping of quadrature magnetic susceptibility/magnetic viscosity of soils by using multi-frequency EMI. Journal of Applied Geophysics, 120, 36-47.

Simpson D., van Meirvenne M., Saey T., Vermeersch H., Bourgeois J., Lehouck A., Cockx L., Vitharana U. W 2009. Evaluating the multiple coil configurations of the EM38DD and Dualem-21S sensors to detect archaeological anomalies. Archaeological Prospection, 16, 91102.

Tabbagh A. 1985. The response of a tree dimensional magnetic and conductive body in shallow depth E.M. prospecting. Geophysical. Journal of the Royal Astronomical. Society, 81$1,215-230$.

Tabbagh A. 1986(a). Sur la comparaison entre la prospection électrique et trois méthodes de prospection électromagnétique pour la détection de contrastes de résistivité associés aux structures archéologiques. Prospezioni Archeologiche, 10: 49-63.

Tabbagh A., 1986(b). What is the best coil orientation in the slingram electromagnetic prospecting method? Archaeometry, 28-2, 185-196.

Tabbagh A., 1986(c). Applications and advantages of the Slingram electromagnetic method for archaeological prospecting. Geophysics, 51-3, 576-584.

Thiesson J, Dabas M, Flageul S 2009. Detection of resistive features using towed slingram electromagnetic induction instruments. Archaeological Prospection, 16: 103-109. 
524 Thiesson J., Kessouri P., Schamper C., Tabbagh A. 2014. Calibration of frequency-domain

525 electromagnetic devices used in near-surface surveying. Near Surface Geophysics, 12, 481526491.

527 


\section{Figure captions}

Figure 1: Composite apparent resistivity map of Vieil-Evreux Gallo-Roman site (RM15MuCEP and $A R P \AA$ channel2); $A R P ®$ system in the upper right with array configuration; studied area outlined in blue.

Figure 2: General scheme of coil configuration in the DualEM-421S instrument (cm units).

Figure 3: Theoretical in-phase (continuous lines) and quadrature responses (dotted lines) versus magnetic susceptibility (left side) and electrical conductivity (right side) for the different HCP and PERP distances from the transmitter in the DualEM-421S.

Figure 4: a) Results of the calibration with the sphere at $\mathrm{z}=60 \mathrm{~cm}$ above the device, b) Results of the calibration with the sphere at $\mathrm{z}=23 \mathrm{~cm}$ above the device
c) Phase separation for the Perp geometries
d) Phase separation for the HCP geometries

Figure 5: DUALEM-421S on its cart pulled by a quad.

Figure 6: Relative quadrature out of phase signal changes (theoretical: grey line, practical dark diamonds) as function of roll angle (in degree) a) HCP 4m, b) PERP 4.1m, c) HCP 2m, d) PERP 2.1m, e) HCP 1m, f) PERP 1.1m.

Figure 7: Position of the 6 VESs and example of inversion for VES $\mathrm{N}^{\circ} 3$

Figure 8: Terre noire plot: spatial variations of the 5 parameters inverted from the 9 quadrature data. 
554 Figure 9: Apparent resistivity maps over the fanum for the 6 different DualEM-421S

555

556

557

558

559

560

561

562

563

564

565

566

567

568

569

570

571

572

573

574

575

576

577

578 quadrature channels and two of the ARPC channels (3D inversion area outlined in blue).

Figure 10: Comparison between the experimental (bold line) values obtained over the small test area and the responses calculated using the result of the ARPC data inversion (thin line).

\section{Table captions}

Table 1: Conductivity values above which the quadrature response differs with more than $10 \%$ from linear response.

Table 2: Coefficients allowing the computation of magnetic field ratio.

Table 3: Measurement dispersion (resistivity in $\Omega \mathrm{m}$ ) at a fixed point with (a) and without (b) engine-turned on.

Table 4: Experimental dispersion and median values observed versus instrument height above the ground surface at VES 3 location and comparison with the values deduced from the VES three layer interpretation where $\rho_{1}=41.3 \Omega \mathrm{m}, \mathrm{e}_{1}=0.6 \mathrm{~m}, \rho_{2}=16.5 \Omega \mathrm{m}, \mathrm{e}_{2}=2.06 \mathrm{~m}$ and $\rho_{3}=26.9$ $\Omega \mathrm{m}$ using the complete expression of the secondary field (Thiesson et al. 2014) and using the approximate cumulative sensitivity response (Wait 1962, Mc Neill 1980). The order of the coil geometries is the following: HCP $1 \mathrm{~m}$, PERP $1.1 \mathrm{~m}$, HCP $2 \mathrm{~m}$, PERP $2.1 \mathrm{~m}$, HCP $4 \mathrm{~m}$ and PERP $4.1 \mathrm{~m}$. 


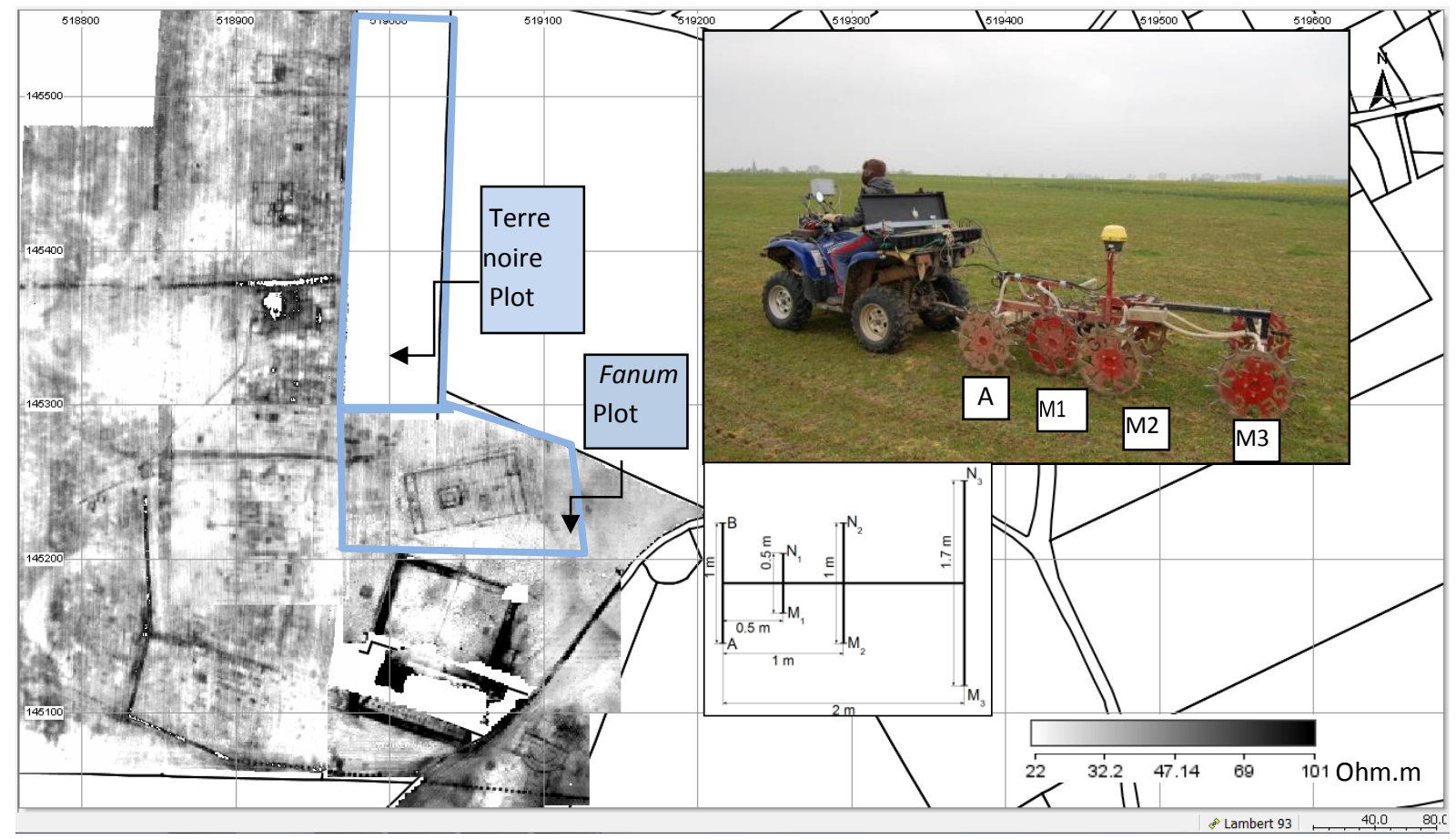

582

583 Fig. 1

584

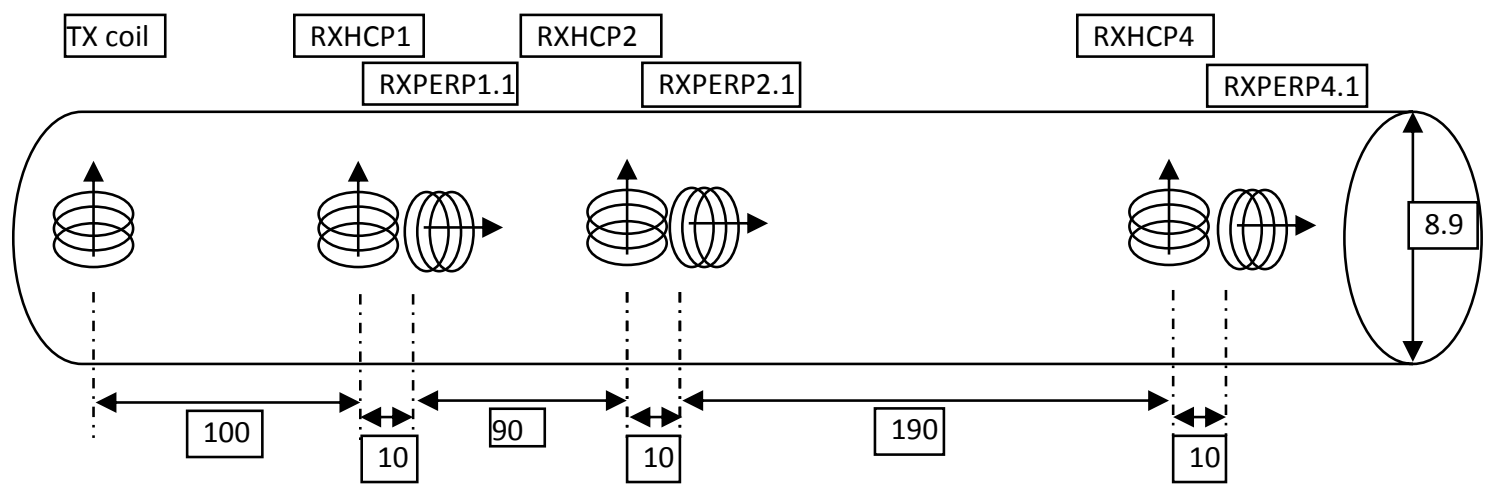

592 Fig. 2 

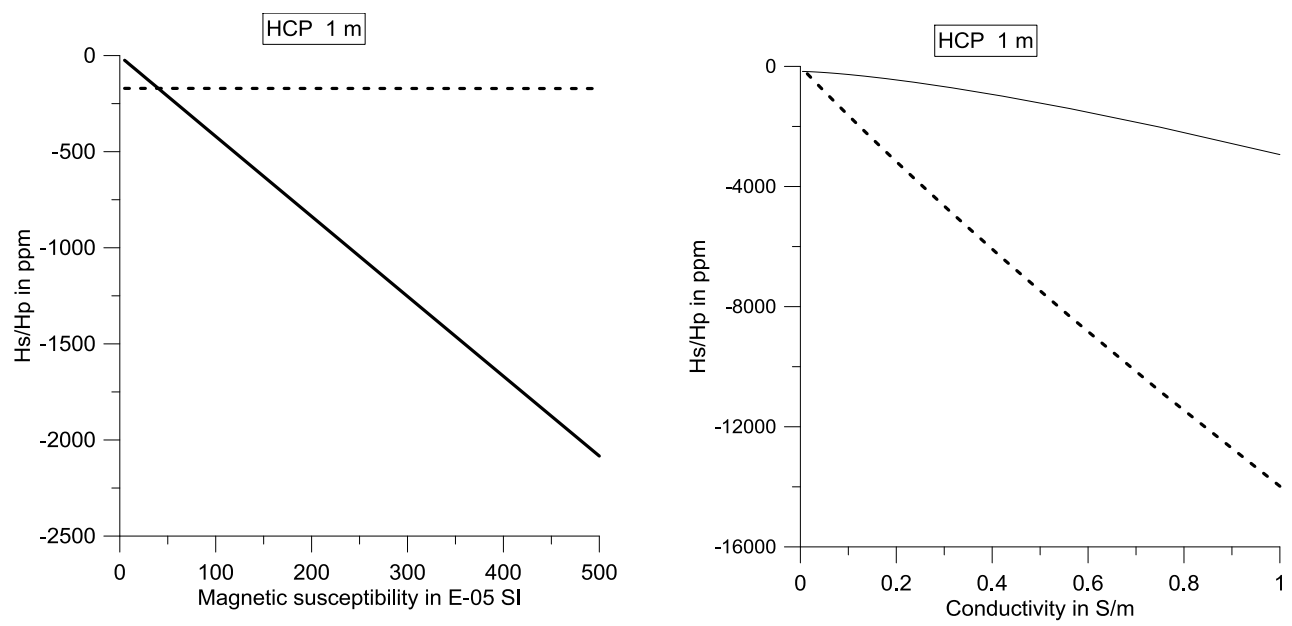

596
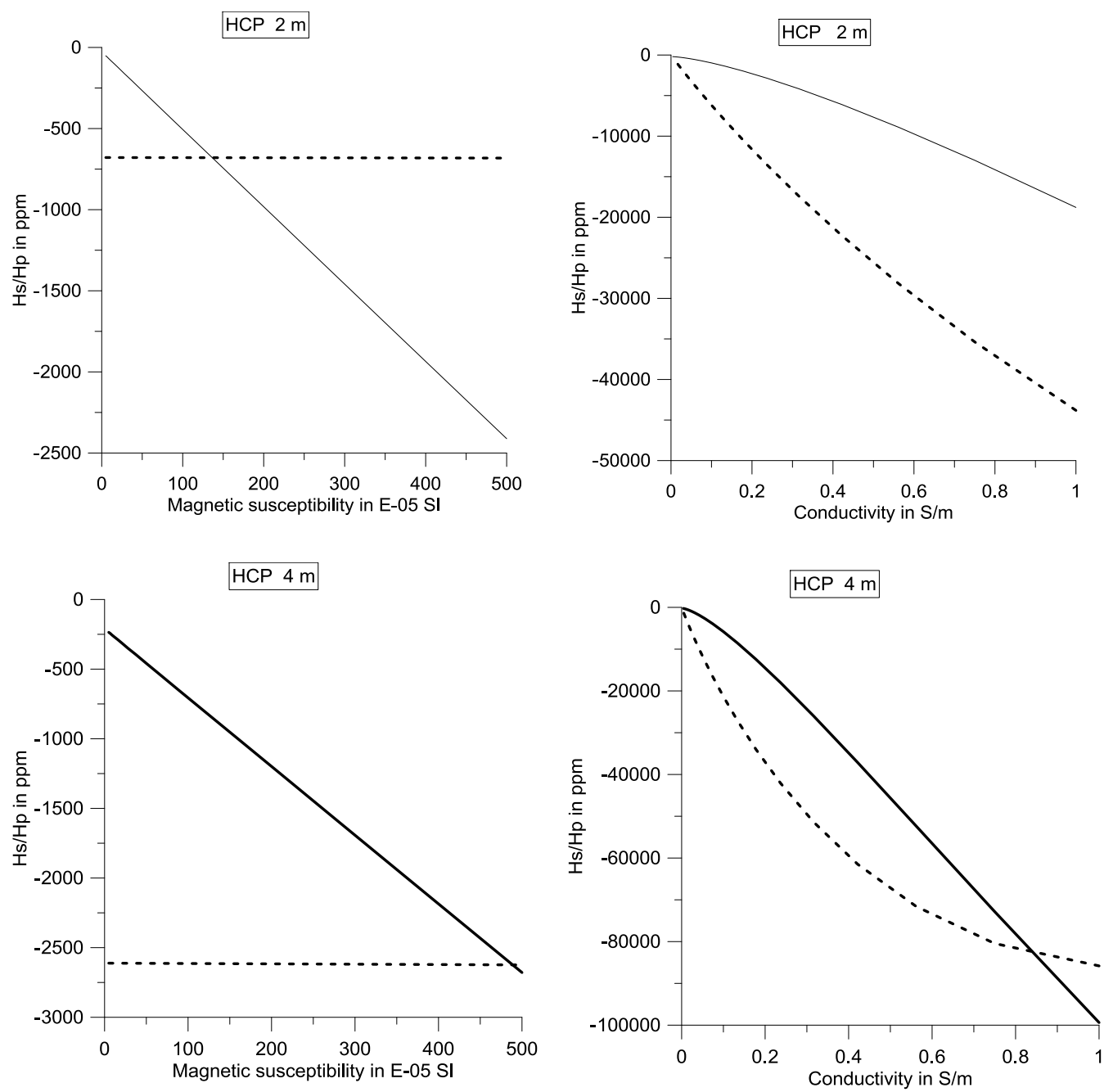

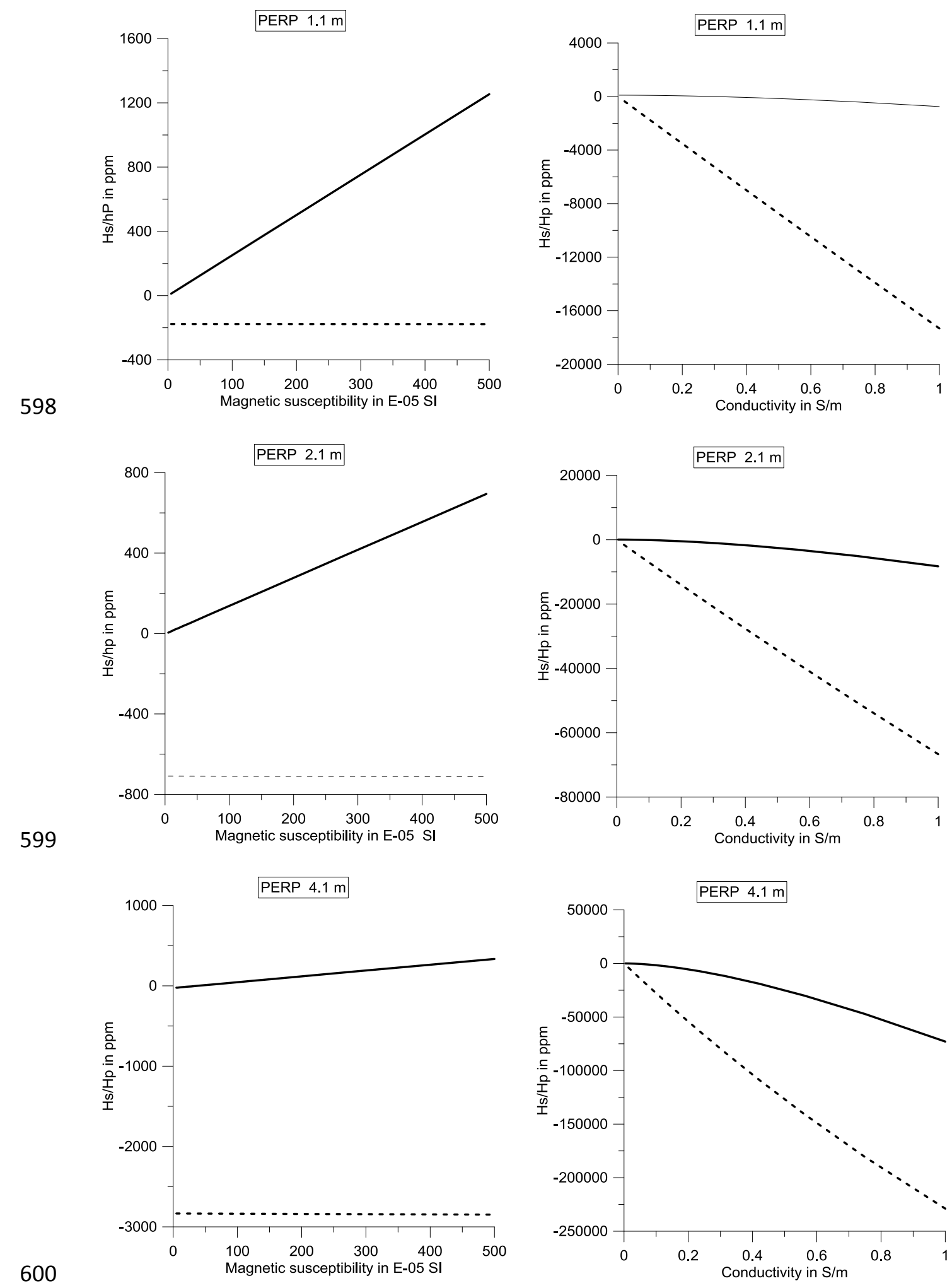

601 Fig. 3 

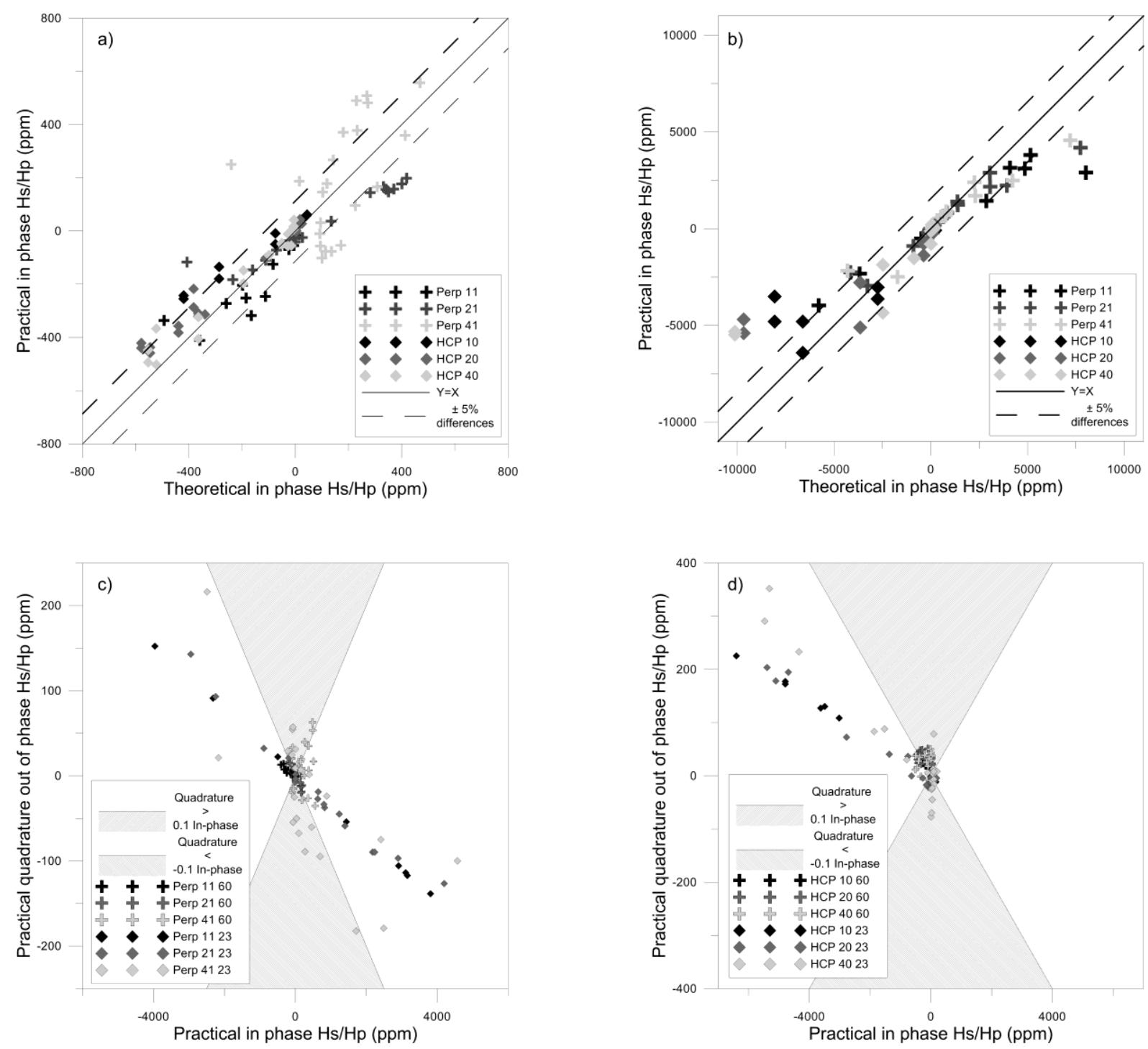

605

$606 \quad$ Fig. 4

607

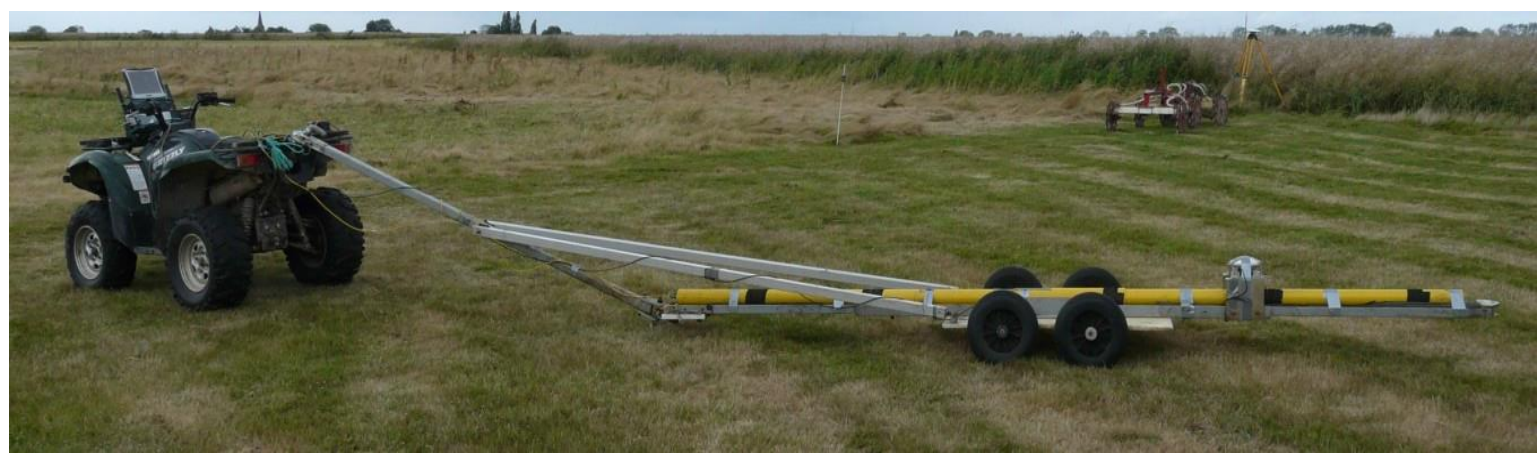

Fig. 5 

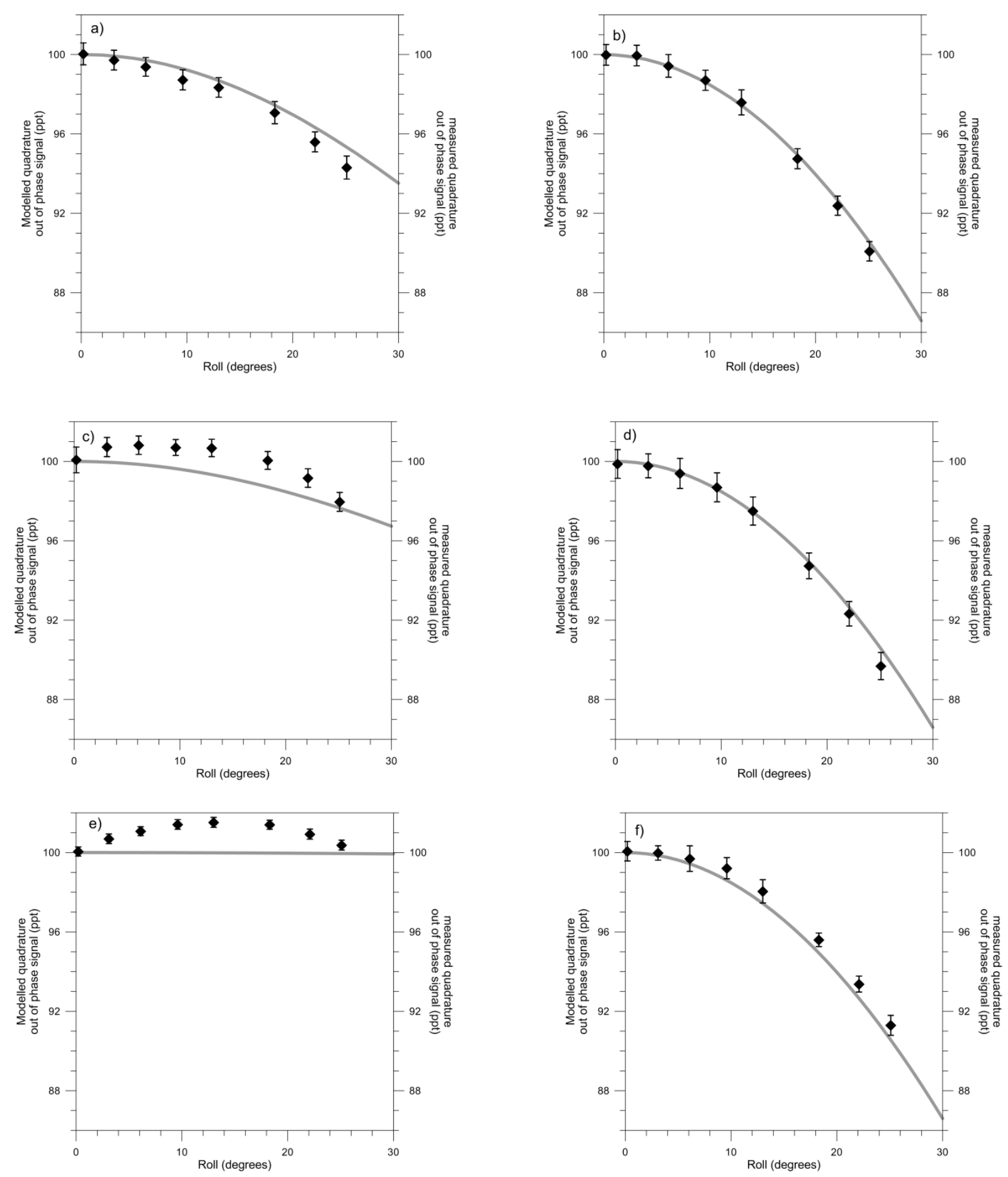

612

613

614

Fig. 6 


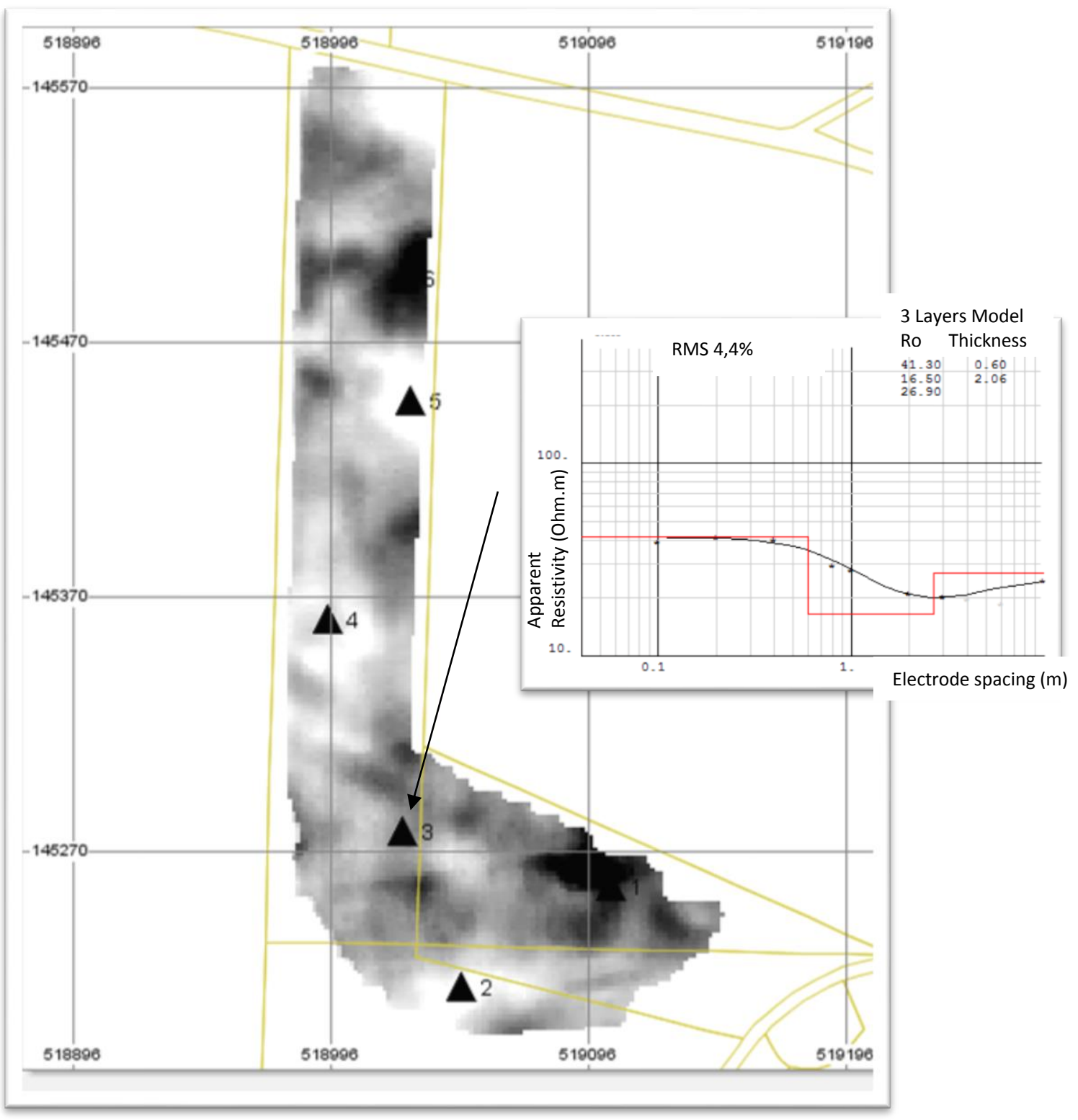

616

$617 \quad$ Fig.7

618 

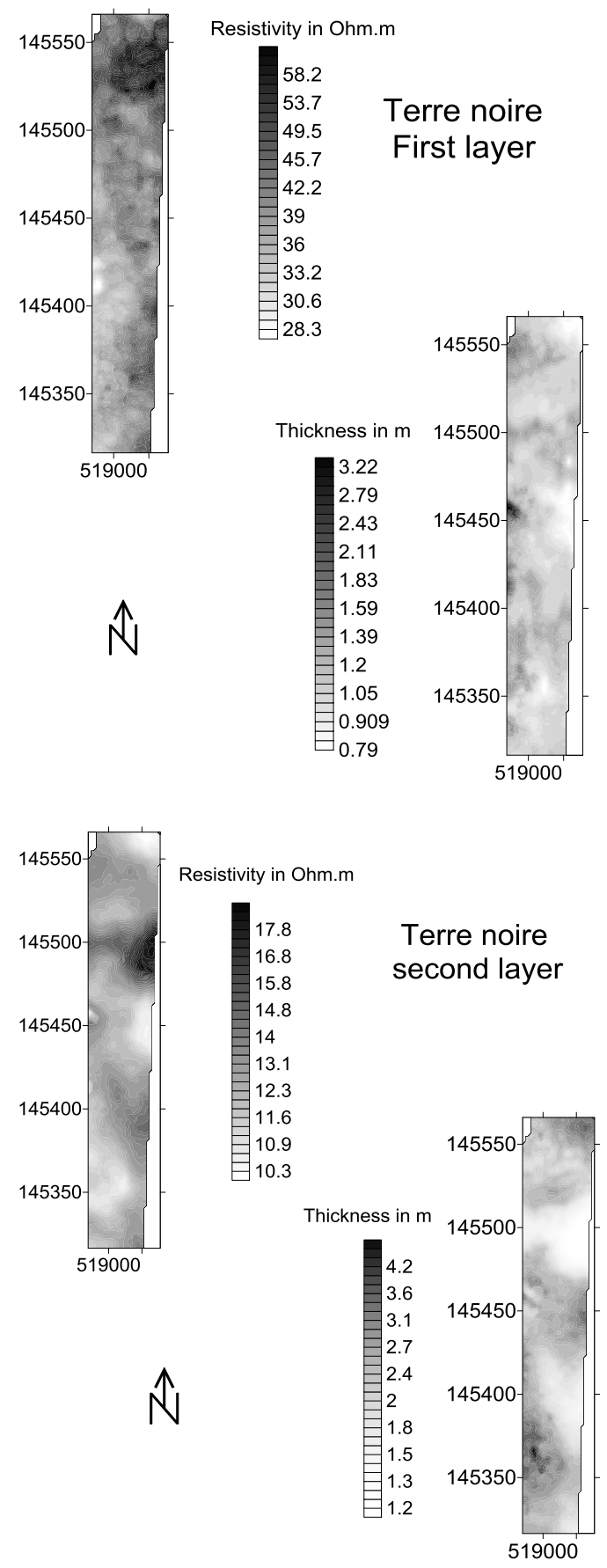


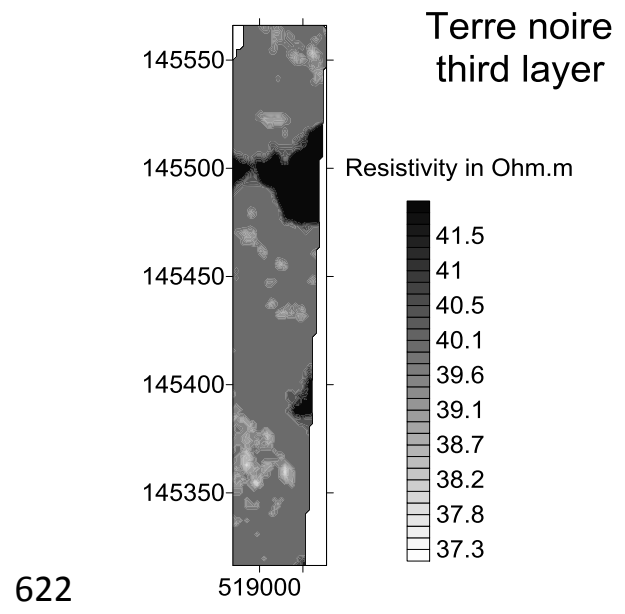

623 Fig. 8

624 


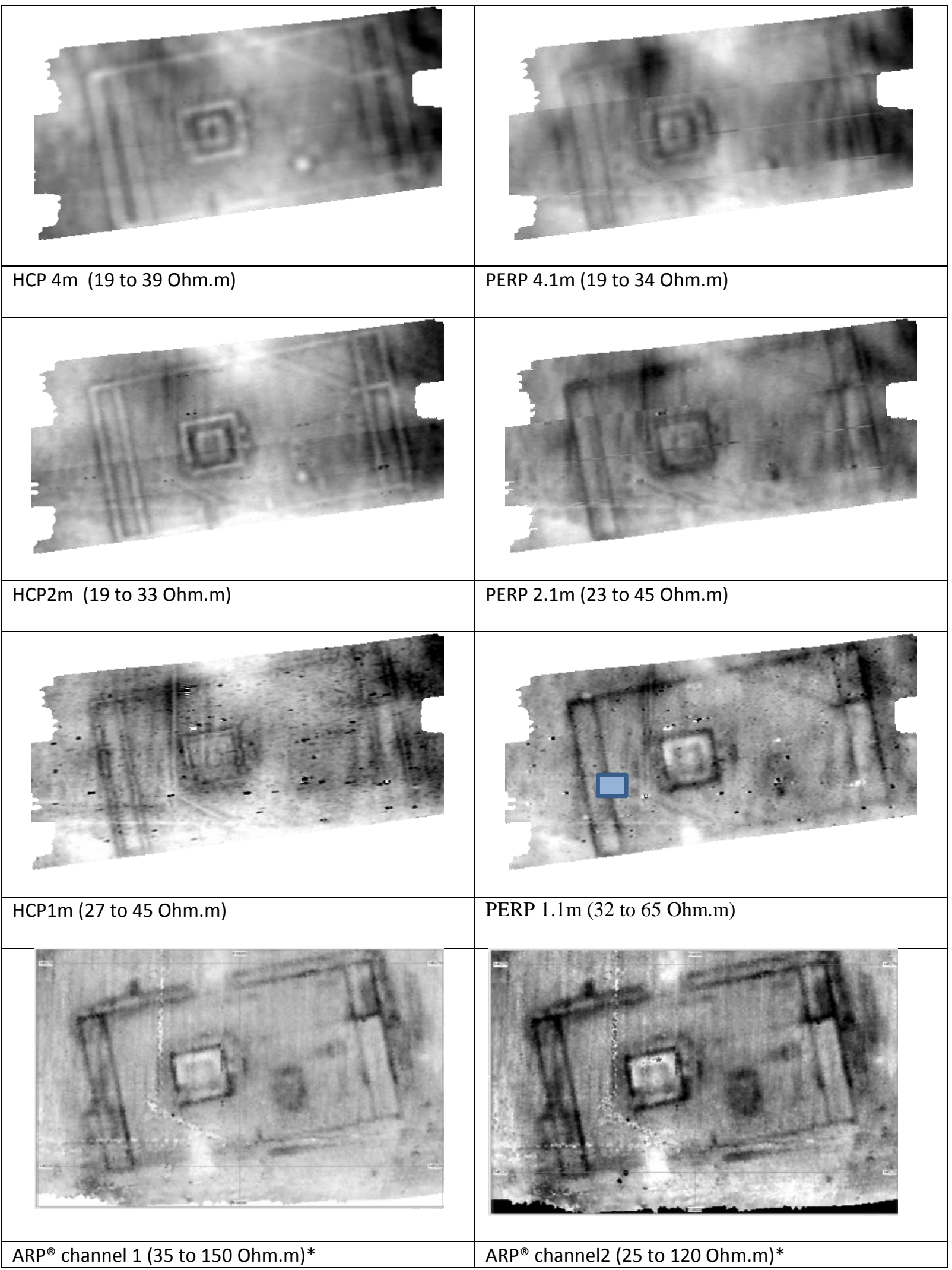



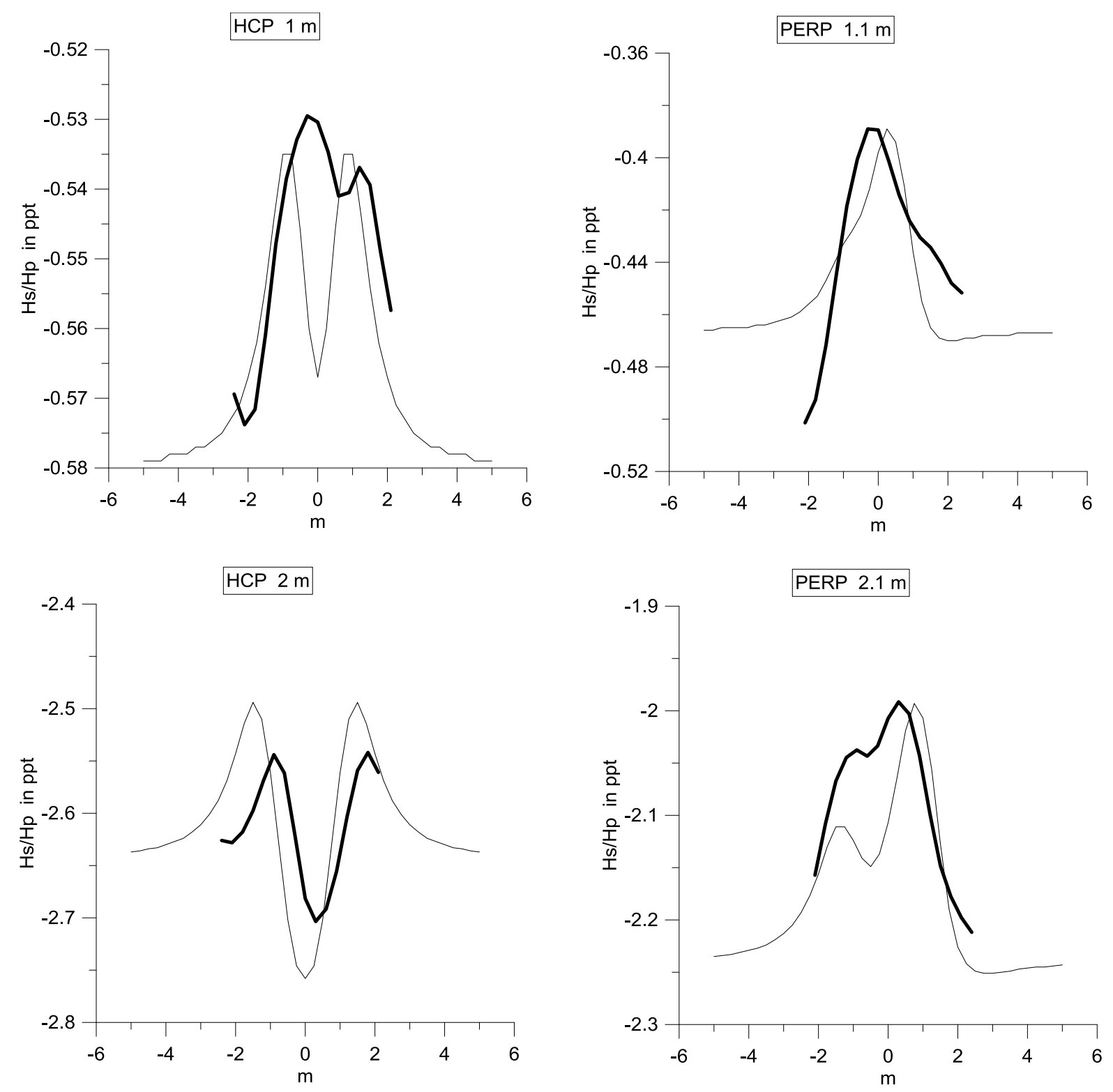

627

628 Fig. 10

629 


\begin{tabular}{|c|c|c|c|c|}
\hline Configuration and spacing & HCP $1 \mathrm{~m}$ & HCP 4m & PERP 1.1 m & PERP 4.1 m \\
\hline$\sigma$ in S/m > to & 0.26 & 0.025 & 2 & 0.40 \\
$(\rho$ in $\Omega . m)<$ to & $(3.8)$ & $(40)$ & $(0.5)$ & $(2.5)$ \\
\hline
\end{tabular}

Table 1

631

\begin{tabular}{|c|c|c|c|c|c|}
\hline HCP1 & HCP2 & HCP4 & PERP1.1 & PERP2.1 & PERP4.1 \\
\hline-0.0178 & -0.0711 & -0.2842 & -0.0215 & -0.0783 & -0.2986 \\
$\mathrm{ppt} / \mathrm{mS} / \mathrm{m}$ & $\mathrm{ppt} / \mathrm{mS} / \mathrm{m}$ & $\mathrm{ppt} / \mathrm{mS} / \mathrm{m}$ & $\mathrm{ppt} / \mathrm{mS} / \mathrm{m}$ & $\mathrm{ppt} / \mathrm{mS} / \mathrm{m}$ & $\mathrm{ppt} / \mathrm{mS} / \mathrm{m}$ \\
\hline
\end{tabular}

632

Table 2

633

634 Table 3

\begin{tabular}{|l|l|l|l|l|l|l|}
\hline Coil distances & $\begin{array}{l}4 . \mathrm{m} \\
\text { HCP }\end{array}$ & $\begin{array}{l}4.1 \mathrm{~m} \\
\text { PERP }\end{array}$ & $\begin{array}{l}2 . \mathrm{m} \\
\mathrm{HCP}\end{array}$ & $\begin{array}{l}2.1 \mathrm{~m} \\
\text { PERP }\end{array}$ & $\begin{array}{l}1 \mathrm{~m} \\
\text { HCP }\end{array}$ & $\begin{array}{l}1.1 \mathrm{~m} \\
\text { PERP }\end{array}$ \\
\hline $\begin{array}{l}\text { Number of } \\
\text { measurements }\end{array}$ & 2749 & 2749 & 2749 & 2749 & 2749 & 2749 \\
\hline Max & 29.3 & 27.3 & 29.3 & 82.6 & 43.3 & 333.3 \\
\hline Min & 27.5 & 25.9 & 26.8 & 73.5 & 40 & 243.9 \\
\hline Average & 28.3 & 26.6 & 27.5 & 78.02 & 41.2245 & 277.8 \\
\hline Variance & 0.062 & 0.036 & 0.021 & 1.824 & 0.153 & 95.290 \\
\hline $\begin{array}{l}\text { Standard } \\
\text { deviation }\end{array}$ & 0.29 & 0.19 & 0.14 & 1.35 & 0.39 & 9.07 \\
\hline
\end{tabular}

635

(a)

\begin{tabular}{|l|l|l|l|l|l|l|}
\hline Coil distance & $\begin{array}{l}4 \mathrm{~m} \\
\mathrm{HCP}\end{array}$ & $\begin{array}{l}4.1 \mathrm{~m} \\
\text { PERP }\end{array}$ & $\begin{array}{l}2 . \mathrm{m} \\
\text { HCP }\end{array}$ & $\begin{array}{l}2.1 \mathrm{~m} \\
\text { PERP }\end{array}$ & $\begin{array}{l}1 \mathrm{~m} \\
\text { HCP }\end{array}$ & $\begin{array}{l}1.1 \mathrm{~m} \\
\text { PERP }\end{array}$ \\
\hline $\begin{array}{l}\text { Number of } \\
\text { measurements }\end{array}$ & 2979 & 2979 & 2979 & 2979 & 2979 & 2979 \\
\hline
\end{tabular}




\begin{tabular}{|l|l|l|l|l|l|l|}
\hline Max & 29.1 & 27.2 & 28.7 & 82.6 & 43.1 & 333.3 \\
\hline Min & 27.6 & 26 & 26.2 & 74.1 & 39.5 & 243.9 \\
\hline Average & 28.32 & 26.60 & 27.53 & 78.02 & 41.28 & 279.7 \\
\hline Variance & 0.029 & 0.033 & 0.023 & 1.842 & 0.150 & 95.9 \\
\hline $\begin{array}{l}\text { Standard } \\
\text { deviation }\end{array}$ & 0.17 & 0.18 & 0.15 & 1.36 & 0.39 & 9.75 \\
\hline
\end{tabular}

636

(b)

637

Table 4

\begin{tabular}{|c|c|c|c|c|}
\hline $\begin{array}{l}\text { Height } \\
\text { above } \\
\text { ground } \\
\text { surface } \\
\text { (m) }\end{array}$ & $\begin{array}{l}\text { Experimental } \\
\text { Dispersion } \\
\text { Third quartile } \\
\text { - first quartile } \\
\text { (ppt) }\end{array}$ & $\begin{array}{c}\text { Median } \\
\text { experimental } \\
\text { value } \\
\text { (ppt) }\end{array}$ & $\begin{array}{l}\text { theoretical } \\
\text { value } \\
\text { deduced } \\
\text { from VES } \\
\text { data } \\
\text { (ppt) }\end{array}$ & $\begin{array}{l}\text { Approximate } \\
\text { cumulative } \\
\text { responses } \\
\text { from VES } \\
\text { data } \\
\text { (ppt) }\end{array}$ \\
\hline 0.045 & $\begin{array}{l}0.005 \\
0.004 \\
0.028 \\
0.024 \\
0.057 \\
0.119 \\
\end{array}$ & $\begin{array}{c}0.552 \\
0.516 \\
2.936 \\
2.670 \\
11.246 \\
12.661 \\
\end{array}$ & $\begin{array}{c}0.722 \\
0.654 \\
3.098 \\
3.043 \\
11.043 \\
13.151 \\
\end{array}$ & $\begin{array}{c}1.169 \\
0.796 \\
4.125 \\
3.667 \\
10.769 \\
17.062 \\
\end{array}$ \\
\hline 0.112 & $\begin{array}{l}0.005 \\
0.004 \\
0.028 \\
0.031 \\
0.057 \\
0.119 \\
\end{array}$ & $\begin{array}{c}0.531 \\
0.449 \\
2.922 \\
2.466 \\
11.161 \\
12.243 \\
\end{array}$ & $\begin{array}{c}0.691 \\
0.570 \\
3.036 \\
2.820 \\
11.003 \\
12.662 \\
\end{array}$ & $\begin{array}{c}1.143 \\
0.757 \\
4.100 \\
3.577 \\
10.921 \\
16.849\end{array}$ \\
\hline 0.179 & $\begin{array}{l}0.005 \\
0.004 \\
0.028 \\
0.031 \\
0.057 \\
0.090\end{array}$ & $\begin{array}{c}0.518 \\
0.400 \\
2.887 \\
2.286 \\
11.076 \\
11.705\end{array}$ & $\begin{array}{c}0.655 \\
0.493 \\
2.966 \\
2.609 \\
10.948 \\
12.180\end{array}$ & \begin{tabular}{|c|}
1.113 \\
0.714 \\
4.067 \\
3.480 \\
11.054 \\
16.628
\end{tabular} \\
\hline 0.246 & $\begin{array}{l}0.005 \\
0.004 \\
0.028 \\
0.023 \\
0.057 \\
0.090 \\
\end{array}$ & $\begin{array}{c}0.493 \\
0.355 \\
2.823 \\
2.122 \\
10.962 \\
11.227 \\
\end{array}$ & $\begin{array}{c}0.617 \\
0.425 \\
2.889 \\
2.410 \\
10.878 \\
11.707 \\
\end{array}$ & \begin{tabular}{c|}
1.081 \\
0.668 \\
4.026 \\
3.378 \\
11.168 \\
16.397 \\
\end{tabular} \\
\hline 0.347 & $\begin{array}{l}0.004 \\
0.002 \\
0.021 \\
0.031 \\
0.057 \\
0.119\end{array}$ & $\begin{array}{c}0.452 \\
0.284 \\
2.709 \\
1.864 \\
10.792 \\
10.541\end{array}$ & $\begin{array}{c}0.560 \\
0.340 \\
2.765 \\
2.134 \\
10.747 \\
11.016\end{array}$ & $\begin{array}{c}1.031 \\
0.598 \\
3.952 \\
3.214 \\
11.305 \\
16.034\end{array}$ \\
\hline 0.449 & $\begin{array}{l}0.005 \\
0.004 \\
0.009\end{array}$ & $\begin{array}{l}0.409 \\
0.224 \\
2.567\end{array}$ & $\begin{array}{l}0.506 \\
0.273 \\
2.633\end{array}$ & $\begin{array}{l}0.983 \\
0.531 \\
3.868\end{array}$ \\
\hline
\end{tabular}




\begin{tabular}{|c|c|c|c|c|}
\hline & $\begin{array}{l}0.031 \\
0.057 \\
0.090\end{array}$ & $\begin{array}{c}1.644 \\
10.565 \\
9.824\end{array}$ & $\begin{array}{c}1.884 \\
10.587 \\
10.343\end{array}$ & $\begin{array}{c}3.045 \\
11.406 \\
15.651\end{array}$ \\
\hline \multirow{6}{*}{0.75} & 0.007 & 0.304 & 0.377 & 0.872 \\
\hline & 0.004 & 0.120 & 0.152 & 0.365 \\
\hline & 0.028 & 2.211 & 2.239 & 3.602 \\
\hline & 0.031 & 1.167 & 1.307 & 2.546 \\
\hline & 0.057 & 9.883 & 9.990 & 11.524 \\
\hline & 0.090 & 8.062 & 8.538 & 14.456 \\
\hline \multirow[t]{6}{*}{1.05} & 0.005 & 0.231 & 0.291 & 0.801 \\
\hline & 0.004 & 0.073 & 0.094 & 0.249 \\
\hline & 0.028 & 1.962 & 1.889 & 3.360 \\
\hline & 0.023 & 0.830 & 0.925 & 2.099 \\
\hline & 0.085 & 9.088 & 9.280 & 11.451 \\
\hline & 0.060 & 6.659 & 7.020 & 13.225 \\
\hline \multirow[t]{6}{*}{1.35} & 0.005 & 0.182 & 0.232 & 0.756 \\
\hline & 0.004 & 0.049 & 0.063 & 0.167 \\
\hline & 0.028 & 1.585 & 1.600 & 3.165 \\
\hline & 0.031 & 0.564 & 0.674 & 1.723 \\
\hline & 0.057 & 8.293 & 8.531 & 11.273 \\
\hline & 0.090 & 5.449 & 5.772 & 12.015 \\
\hline \multirow[t]{6}{*}{1.65} & 0.004 & 0.146 & 0.192 & 0.725 \\
\hline & 0.004 & 0.032 & .044 & 0.107 \\
\hline & 0.028 & 1.322 & 1.367 & 3.013 \\
\hline & 0.031 & 0.446 & 0.506 & 1.415 \\
\hline & 0.057 & 7.526 & 7.795 & 11.049 \\
\hline & 0.090 & 4.539 & 4.963 & 10.869 \\
\hline \multirow[t]{6}{*}{1.95} & 0.005 & 0.117 & 0.162 & 0.704 \\
\hline & 0.004 & 0.024 & 0.033 & 0.062 \\
\hline & 0.028 & 1.145 & 1.181 & 2.898 \\
\hline & 0.023 & 0.353 & 0.390 & 1.163 \\
\hline & 0.057 & 6.816 & 7.103 & 10.817 \\
\hline & 0.090 & 3.792 & 3.954 & 9.810 \\
\hline \multirow[t]{6}{*}{2.25} & 0.005 & 0.098 & 0.139 & 0.690 \\
\hline & 0.004 & 0.17 & 0.026 & 0.026 \\
\hline & 0.028 & 1.003 & 1.030 & 2.810 \\
\hline & 0.031 & 0.290 & 0.307 & 0.955 \\
\hline & 0.057 & 7.696 & 6.467 & 10.597 \\
\hline & 0.090 & 3.195 & 3.506 & 8.845 \\
\hline
\end{tabular}

639

640

641 